\title{
Investigation of Groundwater Potential Using Electromagnetic Method at a Basement Complex Area of University of Abuja, Gwagwalada
}

\author{
Onoka Adokiye $^{1}$ and Mallam Abu ${ }^{1}$ \\ ${ }^{1}$ Department of Physics, University of Abuja, Abuja, Nigeria \\ Corresponding E-mail: adokiyeonoka@gmail.com \\ Received 24-06-2021 \\ Accepted for publication 21-07-2021 \\ Published 23-07-2021
}

\begin{abstract}
The Very Low Frequency Electromagnetic Method (VLF-EM) was used in view of detecting fractured or weathered zones within the University of Abuja Staff Quarters, Gwagwalada, Federal Capital Territory. The VLF -EM data measured along seventeen profiles of $400 \mathrm{~m}$ at inter profile distance of $25 \mathrm{~m}$ and interstation separation of $10 \mathrm{~m}$ were done using the Scintrex ENVI Instrument. The VLF-EM survey revealed features significant to groundwater potential as conductive zones in the Fraser Filter maps and current density pseudosections. Three distinct zones were delineated based on the current density distribution. The fresh basement terrain corresponds to the highly resistive zone with current density value less than -20 . The intermediate zone has current density value range of -20 to 25 typical of rocks and soil component which are slightly resistive to slightly conductive and corresponds to the partially saturated units. The third zone is highly conductive with current density value greater than 30 which includes the saturated weathered or fractured basement, fault zones, clay units and saturated sandy units within the study area. The north eastern, north western (profiles 1-8) and some parts of the southern region (profiles 16 and 17) of the study area show higher conductive zones than the central parts of the study area. This survey has helped in detecting sites that are suitable for groundwater exploration by identifying water bearing fractures and weathered zones in the study area. The areas with high conductivity response are areas with conductive overburden material such as clayey soil, saturated soil, water filled fractures and faults or weathered zone within the basement.
\end{abstract}

Keywords: Basement; Fracture; Groundwater potential; Pseudosection; Terrain

\section{INTRODUCTION}

$\mathrm{W}$ ater as one of the most important substances on Earth is essential for continuity in the life of humans, plants and animals. If a particular area lacks sufficient amount of safe and healthy water, life becomes frustrating for every living thing. Water has various uses which when available impacts on our community positively. Insufficient supply of safe and healthy water or use of contaminated water in a particular region can cause hardship to the public that depend on it for livelihood. Groundwater is the main source of quality and adequate water supply for domestic, agricultural and industrial use in most parts of the world.

The study area is within the basement complex region of Nigeria which are hard rock terrains. Groundwater is trapped within fractured zones, faults or highly weathered basement found within the rocks due to tectonic activities [4]. Ground 
water saturation and yield in any area depends on a number of factors which includes the topography, degree of weathering of the basement rocks, thickness of weathered overburden, degree or size of the fractures and their interconnectivity in the basement rocks.

\section{STUDY LOCATION AND GENERAL GEOLOGY}

The study area located in Gwagwalada Area Council, FCT Abuja, lies between latitudes $8^{\circ} 41^{\prime}$ to $9^{\circ} 04^{\prime}$ North and Longitudes $6^{0} 50^{\prime}$ to $7^{\circ} 06^{\prime}$ East (Fig. 1) [3]. Gwagwalada is a suburb situated along Abuja- Lokoja road. The area is characterized by savannah vegetation with grassland, woodland and shrub land. The great development experienced within the last decade have negatively impacted the vegetal cover. In the FCT, Kuje and Kwali Area councils have good vegetation health while Gwagwalada, Bwari, Abuja and Abaji have poor vegetation health conditions [20].

The study area is underlain by metamorphic and igneous rocks of the Precambrian rocks of the Nigerian basement complex and sedimentary rocks $[14,15,6]$. The study area is situated in the basement complex region of the FCT and groundwater is found in the weathered transition zone, fractures, joints and cracks of the basement with little amount of water in the freshly unweathered bedrock underneath the weathered layers [10]. The major lithologic units found are different textures of granites, gneiss, migmatites, diorites, metasediments and pegmatites $[10,9]$.

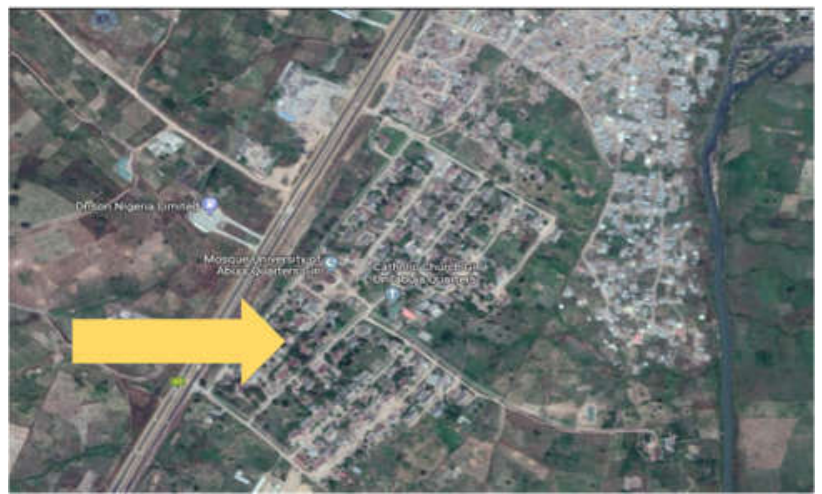

Fig. 1. Location map of study area Imagery (C2019 Maxar

Technologies, Imagery (C2019 CNES / Airbus, Maxar Technologies, Map data (C2019

https://www.google.com/maps/@,8.9885178,7.1473029,1056m/data=!3m1!1e3

Its highest temperatures of $35{ }^{\circ} \mathrm{C}$ is experienced during the dry season (November to March) and in the rainy season (April to October) the temperature drops to $27^{\circ} \mathrm{C}$. Its climate is tropical with an average humidity of $66.6 \%$ [12].

Geophysics is of great importance and serves as a great tool in groundwater surveys and exploration of bedrock geometry [24]. It plays a major part in exploration of healthy and productive groundwater reserves. Boreholes and wells drilled without geophysical study often fail to produce sufficient and healthy water [21]. Over the years, different geophysical methods have been employed in search of groundwater either singly or combined. The choice of geophysical methods used during a field survey depends on the scope or stretch of area to be surveyed, the cost of the survey, geology of the area and availability of software for interpretation of acquired data [18]. The ground conductivity of an area is a reflection of its physical and chemical conditions such as lithology, porosity, degree of water saturation and the presence or absence of voids within the rock $[8,13,16]$.

Electromagnetic method is sensitive to water bearing fractures or weathered basement and this makes it a great tool in groundwater exploration. The Very Low Frequency Electromagnetic method is suitable to identify subsurface conductors. It was employed in this study as a tool to map areas showing high conductivity which is a good indicator of fractured zones, faults or weathered basement with good groundwater prospects. It is an inexpensive, fast and effective method in detecting best sites for groundwater site selection [2].

The Very Low Frequency Electromagnetic Method has proven to be effective in groundwater studies [22, 1, 17, 5, 19]. Its usefulness in groundwater exploration, investigating fracture zones, impact of solid waste disposal in the quality of groundwater, detecting the protective capacity of aquifers cannot be overemphasized.

The aim of this study is to use the VLF Electromagnetic method to determine the subsurface aquiferous zones of the University of Abuja Staff Quarters, Gwagwalada, Abuja and to present information for the best sites to drill boreholes.

\section{MATERIALS AND METHOD}

The Very Low Frequency Electromagnetic (VLF -EM) method was used for the survey. Fig. 2 shows the VLF profiles. The VLF method uses electromagnetic fields to detect objects positioned underneath the surface. Its principle is based on the physical phenomenon that conductive structures on the surface or underground, change the direction and strength of the field generated by remote military communication transmitters located around the world operating at VLF frequency band of $15-30 \mathrm{KHz}$. These transmitted radio signals act as the primary electromagnetic field in the VLF survey. This primary electromagnetic signal penetrates the earth and a smaller secondary field is induced whose field and intensity depends on the conductivity of the ground. This is measured by the VLF receiver.

One part of the secondary field generated oscillates 'inphase' (real or tilt angle) and the other 'out - of - phase' (imaginary or quadrature) with respect to the primary field [7]. The measured imaginary component is useful in determining the quality of the subsurface conductor while the real part is useful in processing the pseudo sections showing the variations of relative apparent current density with depth [4]. Fractured zones are detected as good conductors with high current density values while resistive zones correspond to low 
current density values.

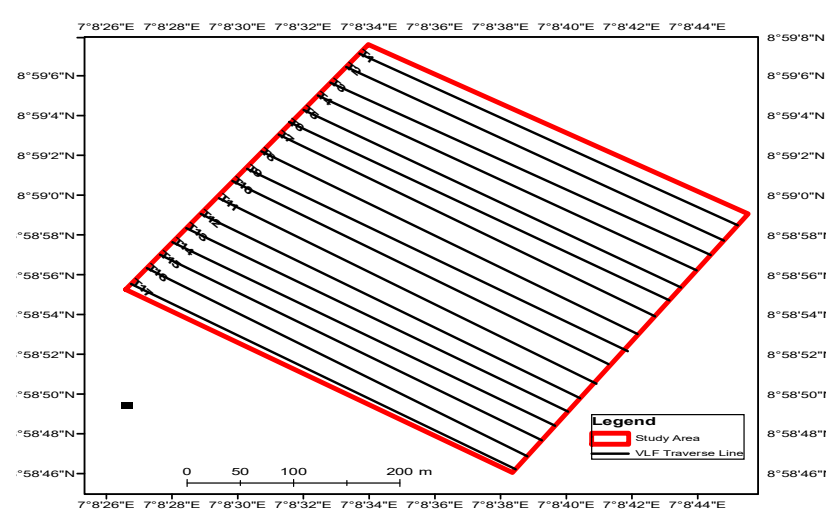

Fig. 2. Study area showing VLF -EM profiles

The VLF-EM method was carried out using the Scintrex Envi Meter in the VLF mode. This survey commenced with visual inspection to locate suitable points for the profiles. Cables, metal pipes and electrical fences can cause strong anomalies so profiles were taken parallel to disturbing cables and in areas void of their effects. Data was collected along seventeen VLF profiles with interstation interval of $10 \mathrm{~m}$ and inter profile interval of $25 \mathrm{~m}$ at the site. This instrument measures the vertical and horizontal components of the secondary electromagnetic field. The real and imaginary components of the data were subjected to Frazer filtering and current density pseudo sections were produced from Karous Hjelt filter. The output of the Karous Hjelt filter is relative current density versus surface position at a chosen depth. The obtained data is filtered using the Fraser Filtering operation [11]:

$\mathrm{F} 1=\left(\phi_{3}+\phi_{4}\right)-\left(\phi_{1}+\phi_{2}\right)$

Where $\phi_{1}, \phi_{2}, \phi_{3}$ and $\phi_{4}$ are consecutive readings of the raw data.

The VLF EM technique is effective for detecting lateral changes in the electrical properties of the subsurface. It is useful in delineating sites that are suitable for groundwater exploration and has proved to be successful in identifying deep water bearing fractures in bedrock [23]

Some advantages of the VLF method is its effectiveness for locating zones of high electrical conductivity even in a hard rock environment with surface or near surface outcrops. Data collection is fast, inexpensive and does not require many field crews. However, some limitations exist because all electrical conductors affect it and limited number of transmitting stations are available. There could also be a sudden interruption in data collection due to break in transmission by stations for scheduled and unscheduled maintenance.

\section{RESULTS AND DISCUSSION}

Profile 1 has a total length of $360 \mathrm{~m}$ running in a NW-SE direction. The conductive zones are indicated by the crossing over of the real and quadrature component at station $100 \mathrm{~m}$ and between $150 \mathrm{~m}$ and $230 \mathrm{~m}$ (Fig. 3). These zones are well displayed as peaks in the filtered real map and in the current density map. The inclination of the apparent current density and the real anomaly shows that the moderately conductive body at station $100 \mathrm{~m}$ is vertically dipping. The other areas on the apparent current density map indicate a highly resistive body at depth from near surface to about $60 \mathrm{~m}$ from station $150 \mathrm{~m}$ to $230 \mathrm{~m}$ resulting from the dry sandy material of compacted dry sand and is sitting on a highly resistive basement.
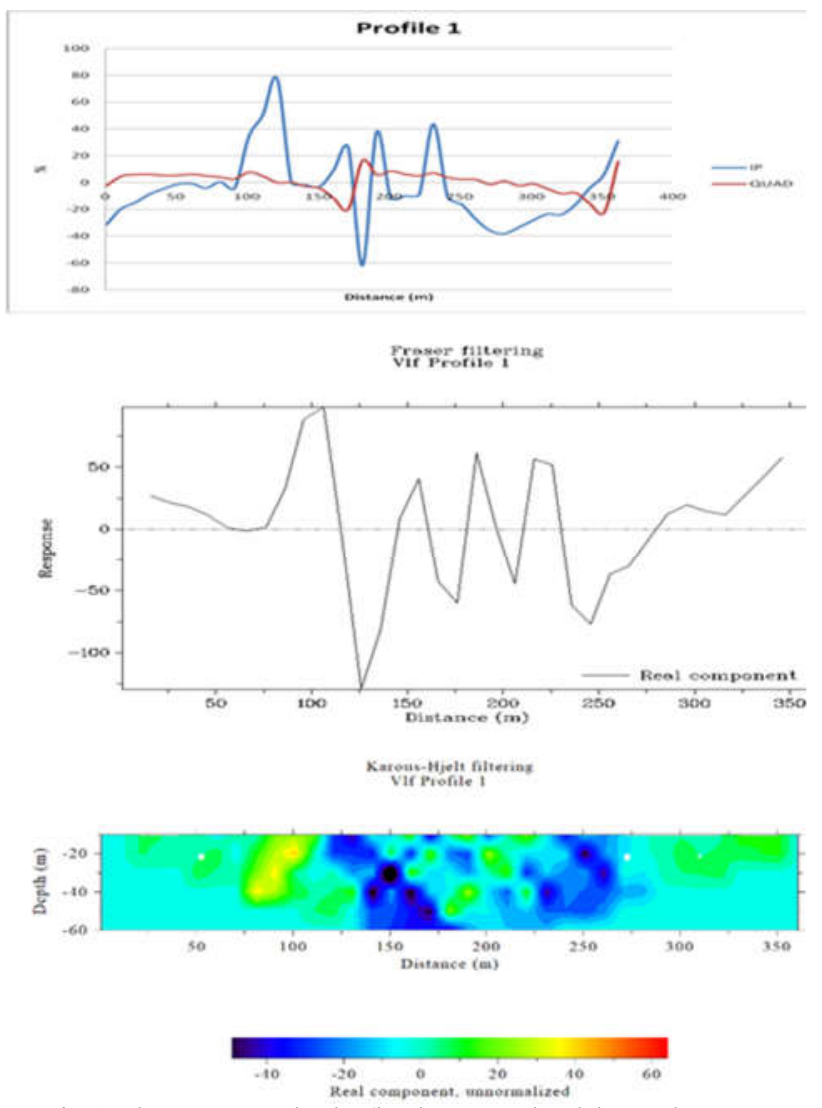

Fig. 3. The VLF anomaly plot (in-phase or real and the quadrature or imaginary component) and current density cross - section for profile 1 .

Profile 2 is parallel to the first profile and is $25 \mathrm{~m}$ away. The cross-over of real and imaginary VLF anomaly along this profile indicates the presence of conductive features around station distance of $50 \mathrm{~m}$ and also at $180 \mathrm{~m}$ (Fig. 4). The filtered real map shows the two peaks representing the conductive zones respectively (Fig. 4). The apparent current density map indicates that the conductive zones are almost vertical and are of shallow depth.

The other area around the station distance between 50 to $100 \mathrm{~m}$ and 200 to $300 \mathrm{~m}$, shows a body of highly resistive soil material occurring at depth near surface to about 60 meters are likely as a result of dry and compacted sandy materials, 
reaching down to the basement. The conductivity variation across this profile is well defined.
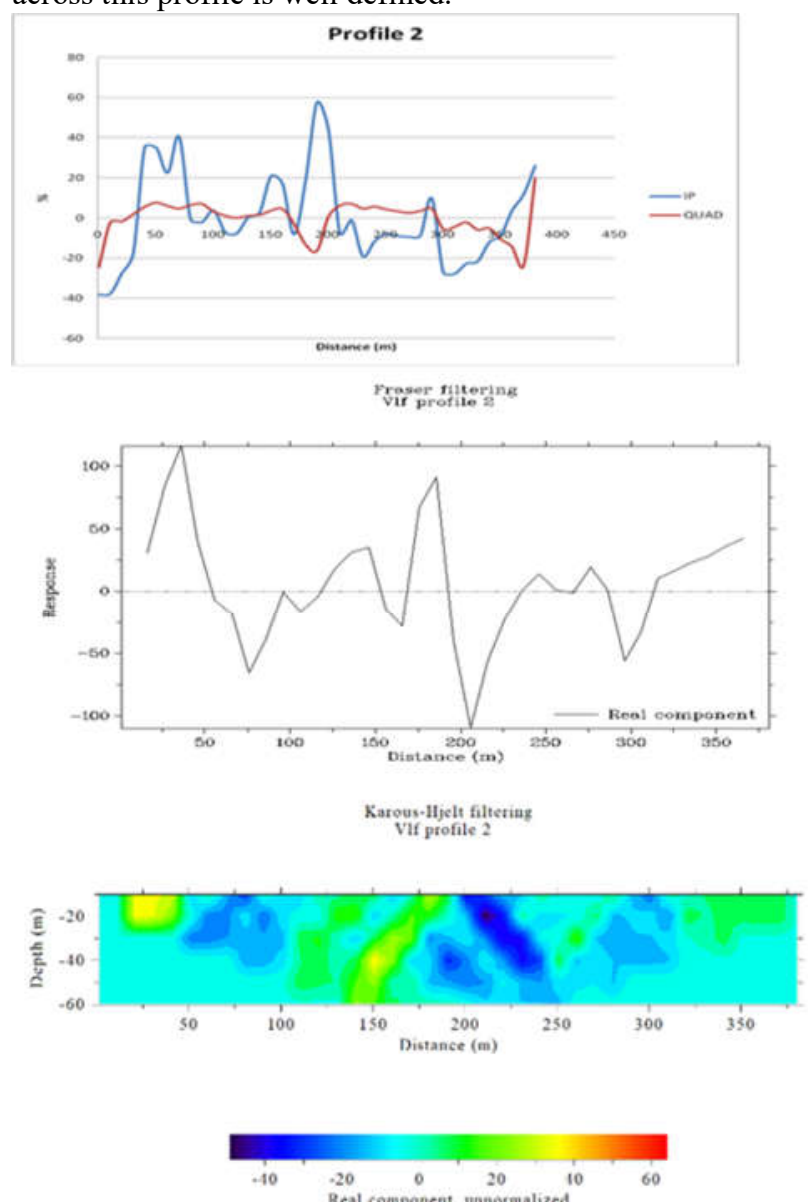

Fig. 4. The VLF anomaly plot (in-phase or real and the quadrature or imaginary component) and current density cross - section for profile 2

Profile 3 has a total length of $360 \mathrm{~m}$. Fig. 5 shows a highly conductive zone of interest between station distance 200 to $250 \mathrm{~m}$ which is likely to be a fractured zone within the basement with water accumulation occurring at depth between $30 \mathrm{~m}$ and $60 \mathrm{~m}$. There are two main areas with high resistivity at station distance $25 \mathrm{~m}$ and at $300 \mathrm{~m}$ as seen. The apparent current density map shows that these two highly resistive zones occur from surface to a relatively shallow depth. The other areas within the profile are moderately conductive due to the mixture of sandy and clayey soil materials.

The cross-over of real and imaginary anomaly line-plot along profile 4 indicates the presence of conductive zones at four major peaks which are at station distance $80 \mathrm{~m}, 150 \mathrm{~m}, 250 \mathrm{~m}$ and $325 \mathrm{~m}$ respectively (Fig. 6) and the filtered real component map enhances these peaks. The highly resistant zones are also seen at station distance $100 \mathrm{~m}, 175$ to $210 \mathrm{~m}$ and at $275 \mathrm{~m}$ respectively. The highly conductive zones are interpreted as clayey soil materials, while the highly resistive zones are interpreted as dry sandy soil component within the profile.
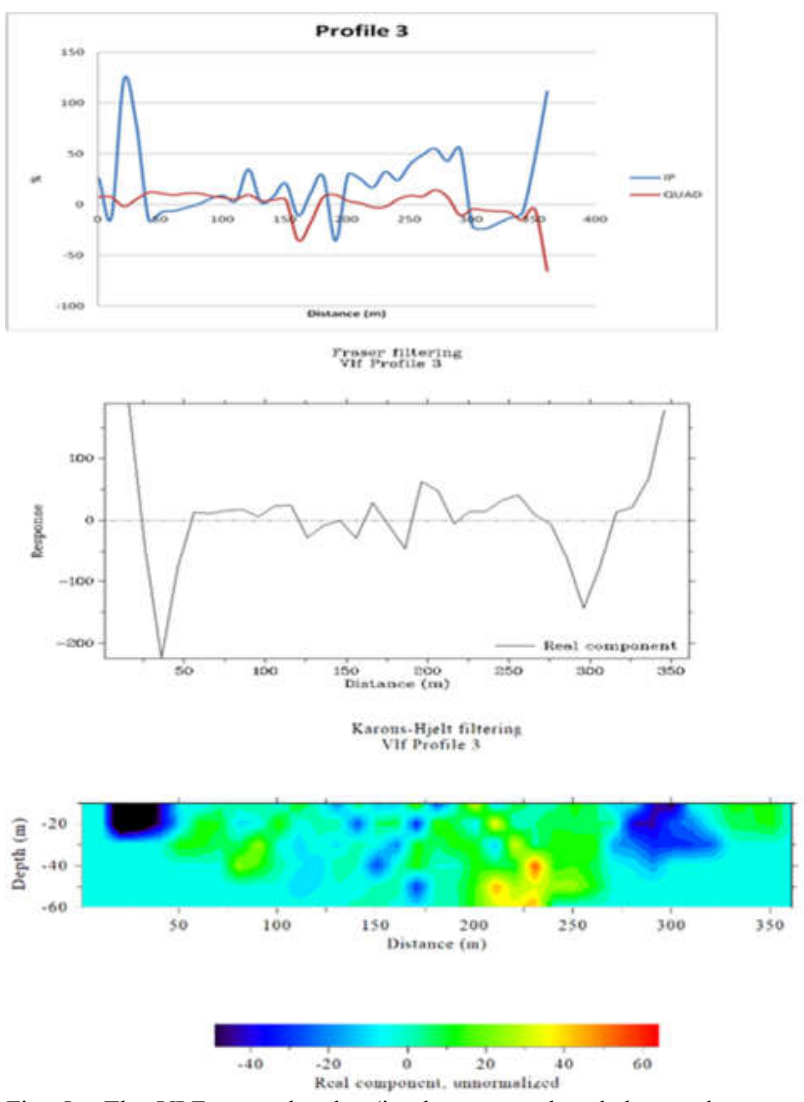

Fig. 5. The VLF anomaly plot (in-phase or real and the quadrature or imaginary component) and current density cross - section for profile 3 .

Profile 5 shows two significant VLF anomaly which is an indication of two main conductive bodies around station distance $80 \mathrm{~m}$ and $270 \mathrm{~m}$ respectively both occurring at shallow depths. Apparent current density cross-section depicts a highly resistive zone between $100 \mathrm{~m}$ to $250 \mathrm{~m}$ extending to a depth beyond $60 \mathrm{~m}$ bounded by a dipping highly resistive body which is likely a faulted zone without fluids. This resulting anomaly is as a result of noise from the iron fencing and the building along this profile. The VLF anomaly, filtered real and the apparent current density map are displayed in Fig. 7.

The VLF anomaly curves for profile 9 (Fig. 8) indicate the presence of two conductive features around stations distance $160 \mathrm{~m}$ and $270 \mathrm{~m}$. The apparent current density cross-section portrays both structures between stations $100 \mathrm{~m}$ and $170 \mathrm{~m}$, and $250 \mathrm{~m}$ and $300 \mathrm{~m}$ and show that they occur from near surface down to $60 \mathrm{~m}$. The zones are good prospect for ground water and the anomaly must have resulted from the clayey soil material down to the fracture zone within the basement with good potential for ground water accumulation. The area around $180 \mathrm{~m}$ and $230 \mathrm{~m}$ indicate a highly resistive body from near surface to depth beyond $60 \mathrm{~m}$. The area shows the likely occurrence of overburden with dry and loose sand 
extending deeper into the highly resistant basement.
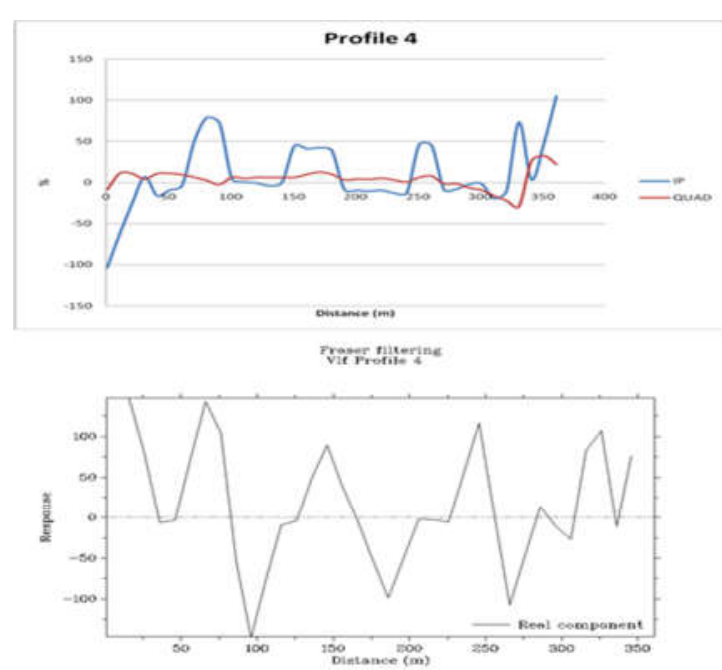

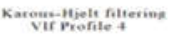
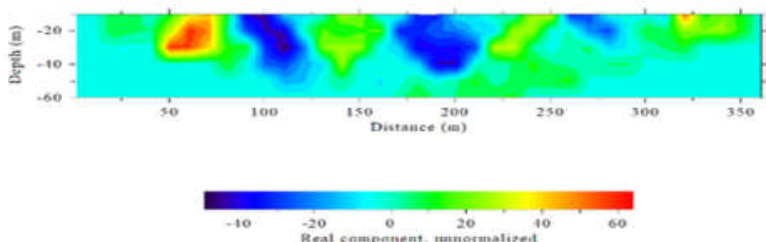

Fig. 6. The VLF anomaly plot (in-phase or real and the quadrature or imaginary component) and current density cross - section for profile 4 .

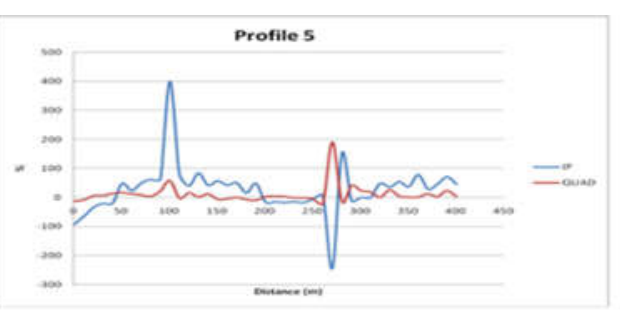

rvition thiterind
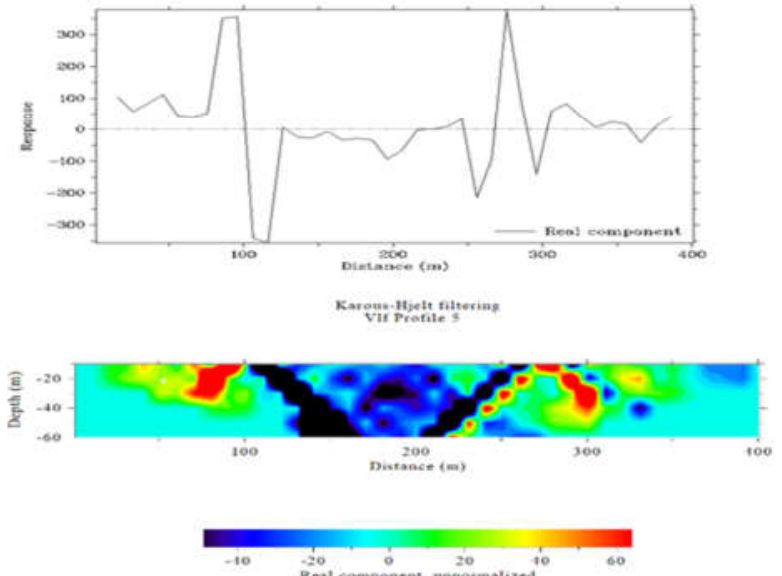

Fig. 7. The VLF anomaly plot (in-phase or real and the quadrature or imaginary component) and current density cross - section for profile 5

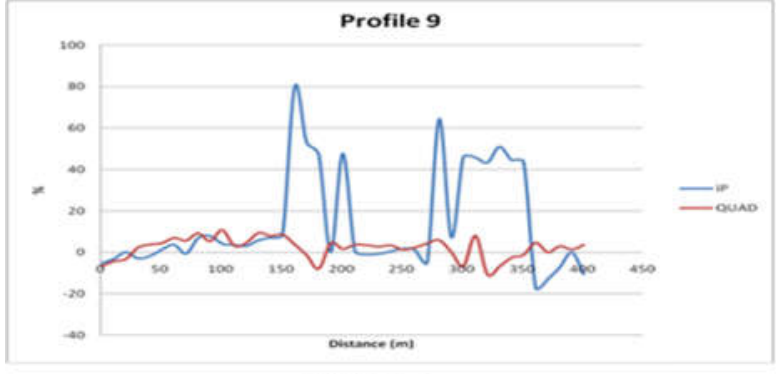

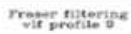
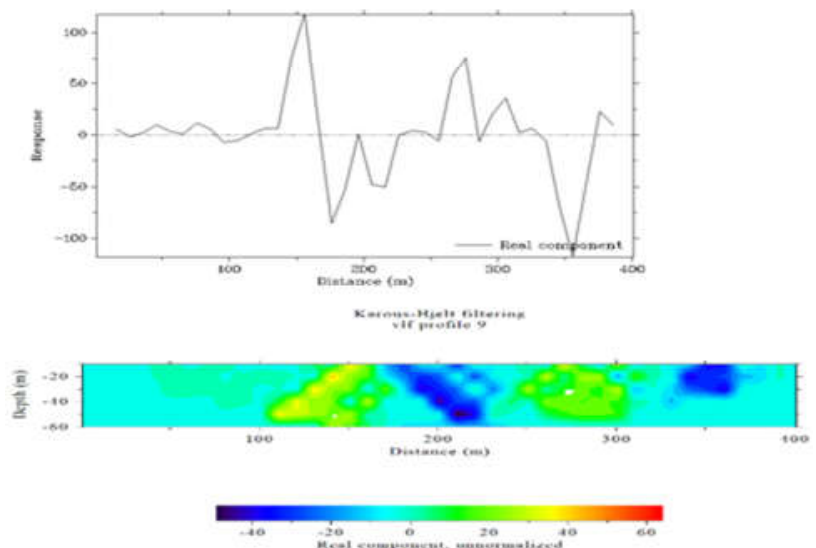

Fig. 8. The VLF anomaly plot (in-phase or real and the quadrature or imaginary component) and current density cross - section for profile 9

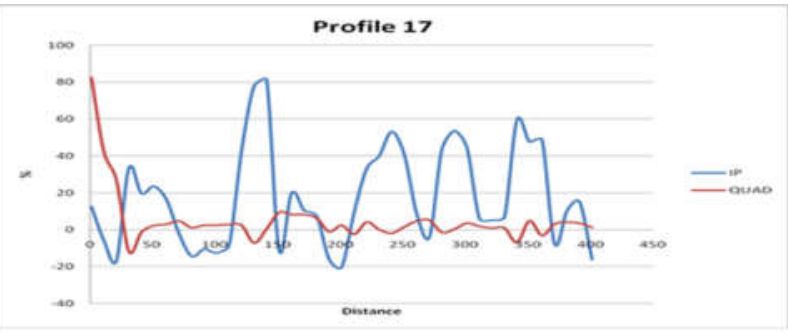

rraser rutering

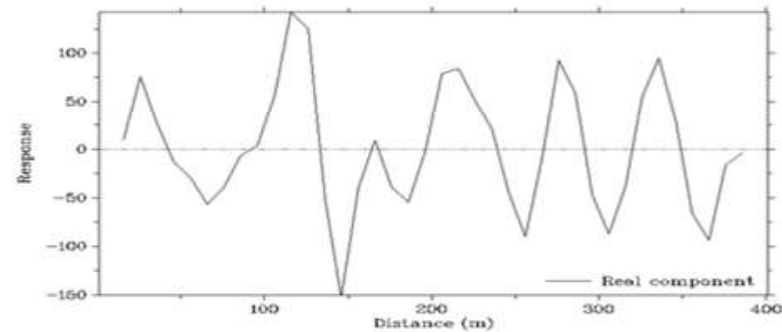

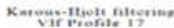

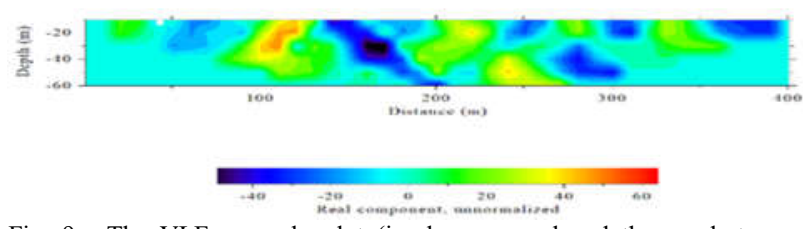

Fig. 9. The VLF anomaly plot (in-phase or real and the quadrature or imaginary component) and current density cross - section for profile 17 
The real and imaginary anomaly plots of profile 17 (Fig. 9) indicate the presence of multiple conductive bodies along this profile seen as positively peaked areas on the filtered real component. The zone with the highest conductivity point at $125 \mathrm{~m}$, in the apparent current density cross-section occurring from near surface to a depth of about $40 \mathrm{~m}$ and bounded by moderately conductive body is regarded as a ground water accumulated zone within the basement rock. The other fractured zone is at the station distance of $240 \mathrm{~m}$ indicated by a highly conductive structure which is regarded as ground water saturated zone within the fractured /faulted basement.

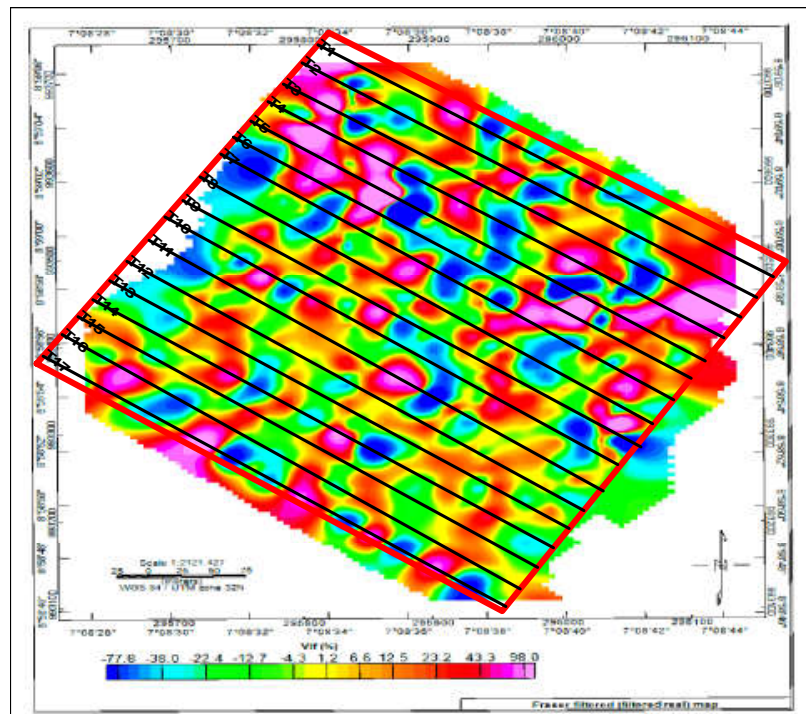

Fig. 10. The 2D map of the filtered real component across the survey area with the traverse line superimposed, lateral (surfacial) conductivity and resistivity distribution is clearly observed. Pink is high conductivity; blue is low conductivity according to the scale.

The filtered real data across the area was gridded to produce a 2-dimensional conductivity map of the study area (Fig. 10). Several factors controlling the conductivity of earth material include, porosity, permeability, metal contents (Sulfides), clay content, permeability and the degree of pore saturation. The map shows the surface variation in the VLF response of various lithological materials which give variations in the conductivity and resistivity across the survey area. It revealed that the study area is characterized by moderately to highly conductive zones with few resistive areas (low conductivity). The areas with high conductivity as are depicted in pinkish coloration and the area with low conductivity (high resistivity) are depicted in bluish coloration, and the others ranging within the average (green to yellow coloration). The areas with high conductivity response are suggestive as areas with conductive overburden material such as clayey soil, saturated soil, water filled fractures and faults or weathered zone within the basement. The other areas with low conductivity are interpreted to be the areas with dry, loose sand material without moisture. Outcrops observed during the field work towards the eastern parts of profiles 7 and 8 and at the northern parts of profiles 10,11,12 and 13 account for the low conductivity (high resistance) values noticed at such points. This VLF EM survey has revealed some geological features with high conductivities believed to be fractured basements. An abandoned borehole sited at profile 3 fall within the area showing high conductivity which is an indication of a groundwater productive zone. Further investigation is required to determine the reason for poor productivity and water quality. Areas corresponding to profiles 4 and 6 show better high conductivity and could be an indication of groundwater potential. The central area of the survey site shows moderate to highly resistive zones with pockets of high conductivity portions. The high resistivity values are due to geological outcrops and buildings.

\section{CONCLUSION}

This study has revealed that the University of Abuja generally has good groundwater potential based on the current density distribution of the VLF data interpreted.

The groundwater prospect of the study area is categorised as high (high conductive zones with current density $>30$ ), moderate (with current density values between -20 and 25) and low (low conductive zones with current density values < $-20)$.

The north eastern, north western (profiles 1-8) and some parts of the southern region (profiles 16 and 17) of the study area show high groundwater potential while the central areas reveal a moderate groundwater potential zone. Due to the fact that one of the major factors controlling conductivity is moisture content makes it easy to use the VLF-EM method for ground water investigation. However, the filtered real map has given us a guide on the areas with high groundwater potential (high conductivity) where further investigations using other geophysical methods can be focused on to determine and interpret the geoelectric parameters of the subsurface. The findings from this study should be considered closely before embarking or commencement of any water project involving siting of boreholes in the study area.

\section{References}

[1] I. M. Abdullahi, N. A. Yelwa, A. Abdulmumin, and N. A. Nabage, "Groundwater Exploration in the Basement Complex around Chibok Area in NorthEastern Nigeria using Vertical Electrical Sounding Method". Nigerian Journal of Basic and Applied Science, vol 24, no. 2, pp. 37-44. 2016.

[2] A. A. Adepelumi, B. D. Ako, T. R. Ajayi, O. Afolabi, and E. J. Omotoso, "Delineation of saltwater intrusion into the freshwater aquifer of Lekki Peninsula, Lagos, Nigeria". Journal of Environmental Geology, vol. 56, no. 5, pp. 927- 933. 2008

[3] P. Akhator, A. Mallam, and N. N. Abdulsalam, "Geo-electric investigation of subsurface water 
resources in Kutunku, Gwagwalada Area Council, Abuja, Nigeria". IOSR Journal of Applied Physics vol. 8, no. 5, pp. 9-18. 2016

[4] S. O. Ariyo, G. O. Adeyemi, and A. O. Oyebamiji, "Electromagnetic VLF Survey for Groundwater Development in a Contact Terrain; A Case Study of Ishara -remo, South Western Nigeria". Journal of Applied Sciences Research, vol. 5, no. 9, pp. 12391246. 2009

[5] A. F. B. Ayad, "Utilization of Very Low Frequency (VLF) Technique in Surveying of Groundwater: A Case Study- Shadnagar-Papireddyguda, A.P., India". International Journal of Environment and Water, Vol. 2, no. 5, pp. 130-141, 2013

[6] O. Balogun, "The Federal Capital Territory of Nigeria": Geography of its Development. Ibadan University Press, pp. 35-37. 2001

[7] F.P. Bosch, and I. Muller, "Continuous gradient VLF measurements: A new possibility for high resolution mapping of Karst structures". First Break 19, pp. 343-350 (Technical report EAGE). 2001

[8] D.L. Corwin, and S.M. Lesch, "Characterizing soil spatial variability with apparent soil electrical conductivity I. Survey protocols". Comput. Electron. Agric. 46, pp. 103-133. 2005

[9] P.N. Dikedi, "Geoelectric Probe for Groundwater in Giri, Nigeria". Global Journal of Science Frontier Research Physics and Space Science. vol 12, no. 2, pp. 43-54. 2012

[10]M. O. Eduvie, T. Olabode, and O. O. Yaya, "Assessment of Groundwater Potentials of Abuja Environments. 29th WEDC International Conference": Towards the Millenium Development Goals, 2003, Abuja, Nigeria.

[11]DC Fraser, "Contouring of VLF-EM data". Geophysics vol. 34, no. 6, pp. 958-967. 1969

[12] S. M. Hassan S. M, Rainfall Variability and Agricultural Land-use Sustainability in Abuja, FCT. (Unpublished). 2008

[13] J. Hutchinson "Electrical imaging of deep clay-mine voids". SAGEEP vol.18, no.1, pp. 247 -279. 2005

[14]A. Mallam, and E. A. Emenike, "Preliminary Findings of Subsurface Characteristics from Direct Current Resistivity Survey of the Federal Capital Territory, Nigeria". International Journal of Pure and Applied Sciences, vol. 2, no. 2, pp 68-76. 2008.

[15]A.B. Mamman, and J.O. Oyebanji, "Nigeria: A people united, a future assured"; Survey of State's. vol. 2 Gabumo Publishing, pp. 736-739. 2000

[16] P. Martinez-Pagan, A. Faz Cano, E. Aracil E, J.M. Arocena' "Electrical resistivity imaging revealed the spatial chemical properties of mine tailing ponds in the Sierra Minera of southeast Spain". Journal of Environmental Engineering and Geophysics. vol.14, no.2, pp. 63-76. 2009

[17] O. Ohwoghere- Asuma, I. F. Chinyem, and O. E. Essi, "Salt water Intrusion Appraisal of shallow aquifer in Burutu Area of the Western Niger Delta with 2D Electrical Resistivity Tomography". Journal of Applied Science, Environment Management vol. 21, no.2, pp. 372-377. 2017

[18] O. B. Olateju, O. O. Moroof, O. M. Ganiyu, A. L. Temitope, O. A. Stephen, and O.F. Julius, "Geophysical Evaluation of Groundwater Potential in part of Southwestern Basement Complex Terrain of Nigeria". Journal of Applied Water Science, vol. 7, no. 2. 2017

[19] J. H. Peter, and H. T. Maggie, "Maximizing Groundwater Production through VLF Mapping Methods". Fast Times, pp. 20-26. 2017

[20] A. B. Rakiya, A. S. Halilu, S. O. Mohammed, H. M. Vaatyough, M. S. Shagari, M. J. Yusuf, J. Jagila, I. Aliyu, R. Eshiet, O. Akinola, C. J. Nsofor, G. Mbaiorga, H. U. Abdulai, S. Modie, A. T. Oje, I. Hamzat, T. Adedeji, and E. S. Ajonye, "Assessing the Drivers of Vegetal cover dynamics in the F.C.T., Nigeria using remote sensing/ GIS techniques". International Journal of Environment, Agriculture and Biotechnology, vol. 3, no.1, pp. 2214-2221. 2018

[21] S. P. Sharma, and V. C. Baranwal, "Delineation of groundwater-bearing fracture zones in a hard rock area integrating Very Low Frequency Electromagnetic and Resistivity data". Geophysics. vol. 57, pp. 155-166. 2005

[22] J.A. Sunday, A. Usman, O. Ologe, and T.O. Lawal, "Detection of Fracture Zones for Groundwater Investigation from Interpretation of VLF-EM Anomalies of Kwara State Polytechnic Ilorin and its Environs". Global Journal of Human- Social Science: Geography, Geo-Sciences, Environmental Science \& Disaster Management. vol. 19, no. 1, pp. 27-41. 2019

[23] N. Sundarajan, and G. Nandakumar, "VES and VLFAn Application to Groundwater Exploration, Khammam, India". The Leading Edge, vol. 26, no. 6, pp. 708-716. 2007

[24] O.O. Esther, D.D. Matoh, O.A. Hyacinth and M.D. Amina, "Electrical Resistivity Investigation of the Bedrock Geometry of the Northern Sector of Kujama Prison Farm Kaduna, Nigeria". PHYSICSAccess, vol.1, no.1, pp. 14-19. April 2021. Accessed on: June, 23,2021 , https://doi.org/10.47514/phyaccess.2020.1.1.000 [online] 